\title{
Extraction of Phytochemical Compounds from Eucheuma cottonii and Gracilaria sp using Supercritical $\mathrm{CO}_{2}$ Followed by Subcritical Water
}

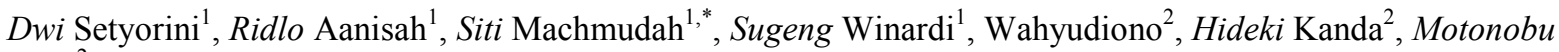 \\ Goto $^{2}$ \\ ${ }^{1}$ Department of Chemical Engineering, Institut Teknologi Sepuluh Nopember, Surabaya 60111 INDONESIA \\ ${ }^{2}$ Department of Materials Process Engineering, Nagoya University, Furo-cho, Chikusa-ku, Nagoya 464-8603 JAPAN
}

\begin{abstract}
Extraction of phytochemical compounds (such as $\beta$-carotene, linoleic acids, carrageenan, and polyphenols) from algae Eucheuma cottonii and Gracilaria $s p$ with supercritical $\mathrm{CO}_{2}$ followed by subcritical water has been investigated. Supercritical $\mathrm{CO}_{2}$ extraction was carried out at pressure of $25 \mathrm{MPa}$, temperature of $60^{\circ} \mathrm{C}, \mathrm{CO}_{2}$ flowrate of $15 \mathrm{ml} / \mathrm{min}$, and ethanol flowrate of $0.25 \mathrm{ml} / \mathrm{min}$. To determine the content of carotenoids and linoleic acids, the extracted compounds were analyzed using a spectrophotometer UV-Vis. The residue of algae starting material was subsequently extracted by subcritical water at pressures of 3,5 , and $7 \mathrm{MPa}$, and temperatures of $120,140,160$, and $180{ }^{\circ} \mathrm{C}$. Carrageenan extracted by subcritical water was analyzed using Fourier Transform Infra Red (FTIR), while the total phenolic compound was analyzed with UV-vis spectrophotometer. Moreover, the antioxidant efficiency of extract was also examined by DPPH assay method. Based on the analytical result, $\beta$-carotene and linoleic acid content in Eucheuma cottonii were 209.91 and $321.025 \mu \mathrm{g} / \mathrm{g}$ sample, respectively. While $\beta$ carotene and linoleic acid content in Gracilaria sp were 219.99 and $286.52 \mu \mathrm{g} / \mathrm{g}$ sample, respectively. The optimum condition of subcritical water extraction was at $180^{\circ} \mathrm{C}$ and $7 \mathrm{MPa}$. At this condition, the highest TPC content in the extract from Eucheuma cottonii and Gracilaria sp were $18.51 \mathrm{mg} \mathrm{GAE} / \mathrm{g}$ sample and $22.47 \mathrm{mg} \mathrm{GAE} / \mathrm{g}$ sample, respectively; while the highest yield of carrageenan extracted from Eucheuma cottonii and Gracilaria sp were 61.33 and $65.54 \mathrm{~g} / 100 \mathrm{~g}$ dried algae, respectively. At the same condition, the antioxidant efficiency was $0.513 \mathrm{~min}^{-1}$ for Eucheuma cottonii and 0,277 $\mathrm{min}^{-1}$ for Gracilaria sp. Based on the results the extraction method effectively separated non-polar and polar compounds, then increased the antioxidant efficiency of extract.
\end{abstract}

\section{Introduction}

Seaweed is one of the country's sources of foreign exchange and a source of income for coastal communities. In addition, it can be used as food, drinks and medicines. Alginate and carrageenan are important components in the food and pharmaceutical industries. Most of the seaweed in Indonesia is exported in dry form. To increase the added value of seaweed and reduce the imports of its processed products, the processing of seaweed into carrageenan is needed to be developed [1].

One of the most widely grown algae in Indonesian is Gracilaria $s p$, which is a jelly producer. However, the use of this algae was limited for food and medicinal products, and there was no further development effort on other products that have higher economic value [2]. One of the seaweed contents that is useful in the field of industry is phytochemical compounds. The main component of algae is polysaccharides, which can reach $40-70 \%$ dry weight depending on the type of algae and its growing environment. In addition to polysaccharides, algae contain some proteins, fats, minerals, and vitamins.

In order to separate the phytochemical compounds of algae, an extraction method was developed by combination of two extraction methods namely supercritical and subcritical fluids extractions.

Supercritical fluid extraction is a process of extraction using supercritical fluids as solvents. This extraction technology utilizes the solvent strength and physical properties of pure components or mixtures at their critical temperatures and pressures in phase equilibrium [3]. The principle of the supercritical fluid extraction method is the process of separating the component above the critical pressure and critical temperature of a solvent fluid. $\mathrm{CO}_{2}$ is the most solvent used in supercritical fluid extraction method because it is non-toxic, nonflammable, and easy available. Supercritical $\mathrm{CO}_{2}$ allows non-polar compounds to be extracted from a natural product [4]. 
In this work, supercritical $\mathrm{CO}_{2}$ extraction was carried out at constant temperatures and pressures to extract $\beta$ carotene and linoleic acid from Eucheuma cottonii and Gracilaria sp algae. $\beta$-carotene and linoleic acid are valuable compounds with high antioxidant activity.

Subcritical water extraction or hydrothermal extraction or pressurized hot water extraction is one such alternative. Water under subcritical conditions is known as a 'natural and green' method for product extraction and has received increased attention as an important alternative to the conventional separation methods. Water under subcritical conditions can be applied to extract polar organic compounds or to decompose lignocellulosic materials to produce valuable compounds such as saccharides and aromatic organic acids. This method has been applied to recover protein, amino acids, and phenolic compounds [5].

In this work, subcritical water extraction was carried out at various temperatures and pressures to extract carrageenan and total phenolic compounds (TPC) from Eucheuma cottonii and Gracilaria sp algae residue of supercritical $\mathrm{CO}_{2}$. The effect of pressure and temperature on the yield of carrageenan and TPC was investigated. The antioxidant efficiency of extract was also investigated.

\section{Experimental Section}

\subsection{Materials}

Eucheuma cottonii and Gracilaria sp algae used for starting material was purchased from Pamekasan, Madura. Prior to the extraction, Eucheuma cottonii and Gracilaria sp algae were rinsed by using distilled water to remove the impurities and salts. Then, they were ground into fine using a millser. Next, they were dried at $60^{\circ} \mathrm{C}$ for one day until no standing moisture was visible. The Folin-Ciocalteau's Reagent, 1,1 diphenyl-2picrylhidrazil (DPPH) and gallic acid $\left(\mathrm{C}_{7} \mathrm{H}_{6} \mathrm{O}_{5}\right)$ were purchased from Sigma-Aldrich Japan (Tokyo, Japan). Sodium carbonate $\left(\mathrm{Na}_{2} \mathrm{CO}_{3}\right)$, methanol $\left(\mathrm{CH}_{3} \mathrm{OH}, 99.7 \%\right)$, and ethanol $\left(\mathrm{C}_{2} \mathrm{H}_{5} \mathrm{OH}, 99.5 \%\right)$ were supplied by Merck (Germany). Standard carotene (98\%) and linoleic acid (98\%) were purchased from Wako Pure Chemical Industries Ltd. (Osaka, Japan). They were used without further purification.

\section{$2.2 \quad$ Experimental setup}

In this work, the supercritical $\mathrm{CO}_{2}$ and subcritical water extraction were conducted in a semi-batch process. The main apparatus of both processes consist of a highpressure pump (200 LC Pump, Perkin Elmer, Germany), heater (Linn High Therm GmbH, model VMK 1600, Germany), reactor (10 $\mathrm{mL}$ in volume; Thar Design Inc., USA) and back pressure regulators (BPR; AKICO, Japan). Both sides of the reactor were equipped with removable threaded covers included stainless-steel filters (0.1-1.0 $\mu \mathrm{m})$. The $1 / 16$ in. stainless-steel tube was used to introduce liquid $\mathrm{CO}_{2}$ or hot water from the pre-heater to the reactor, which was located in the heater.

\subsubsection{Supercritical $\mathrm{CO}_{2}$ extraction}

In Supercritical $\mathrm{CO}_{2}$ extraction process, initially, $12 \mathrm{~g}$ of starting material was loaded into the extractor among glass beads put on the both side of extractor inlet and outlet to prevent channeling. Then the extractor was installed in the heater. $\mathrm{CO}_{2}$ as a solvent was then pumped at a flow rate of $15 \mathrm{~mL} / \mathrm{min}$ using an HPLC (High Performance Liquid Chromatography) pump to reach an operating pressure. Besides that, ethanol was then pump at a flow rate $0.25 \mathrm{~mL} / \mathrm{min}$ using an HPLC pump. The mixture of ethanol and $\mathrm{CO}_{2}$ was flowed into extractor. The pressure was controlled by adjusting back pressure regulator (BPR) that includes a heater. Furthermore, the $\mathrm{CO}_{2}$ and ethanol was heated using a preheater and heater to achieve an operating temperature. To ensure the temperature in the extractor according to the desired temperature, temperature in the inlet and outlet of extractor were measured by thermocouples $\left(T_{1}\right.$ and $\left.T_{2}\right)$. Extraction solution was collected every $30 \mathrm{~min}$ in a collection vial. The $\mathrm{CO}_{2}$ was flowed into environment after passed through gas flow meter. Extract was then stored in a refrigerator. The schematic diagram of supercritical $\mathrm{CO}_{2}$ extraction apparatus is shown in Figure 1. The extraction was carried out at temperatures of $60^{\circ} \mathrm{C}$ and pressures of $25 \mathrm{MPa}$ for 3 hours.

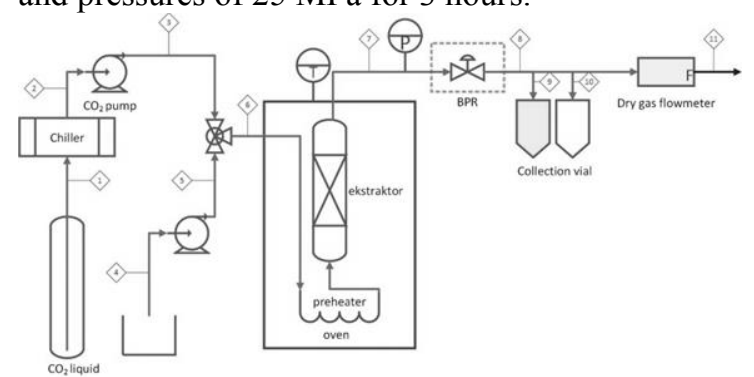

Fig. 1. Apparatus for supercritical $\mathrm{CO}_{2}$ extraction

\subsubsection{Subcritical water extraction}

In subcritical water extraction process, initially, $1 \mathrm{~g}$ of residue from supercritical $\mathrm{CO}_{2}$ extraction was loaded into the extractor among glass beads put on the both side of extractor inlet and outlet to prevent channeling. Then the extractor was installed in the heater. Water as a solvent was then pumped at a flow rate of $1 \mathrm{~mL} / \mathrm{min}$ into the extractor using an HPLC pump to reach an operating pressure. The pressure was controlled by adjusting back pressure regulator (BPR), and was monitored by pressure gauge. Furthermore, the water was heated using a preheater and heater to achieve the operating temperature. To ensure the temperature in the extractor according to the desired temperature, temperature in the inlet and outlet of extractor were measured by thermocouples $\left(T_{1}\right.$ and $\left.T_{2}\right)$. The extract solution was cooled by a cooler and then passed the filter and collected in a collection vial every $30 \mathrm{~min}$. Extract solution was then stored in a refrigerator. The schematic diagram of subcritical water extraction apparatus is shown in Figure 
2. The extraction was carried out at temperatures of $120-$ $180^{\circ} \mathrm{C}$ and pressures of $1-5 \mathrm{MPa}$ for 3 hours.

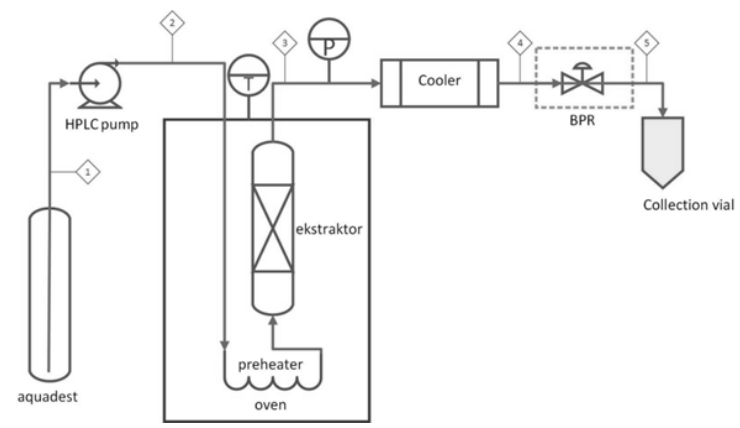

Fig. 2. Apparatus for hydrothermal extraction

\subsection{Analytical method}

Analysis of phenolic compounds, $\beta$-carotene, linoleic acid content, and antioxidant activity in the extracts was conducted using Genesys 10 UV-Vis Scanning Spectrophotometer (Thermo Fisher Scientific, Waltham, MA), allowing spectra between $190 \mathrm{~nm}$ to $1,100 \mathrm{~nm}$. Liquid products were analyzed in quartz cuvette with 1 $\mathrm{cm}$ path length. The solid products collected at each operating condition were analyzed by a Spectrum One FT-IR Spectrophotometer (Perkin-Elmer, Ltd., England) to determine the structure of the solid products after the subcritical water extraction. The scanning wavenumber ranged was from $4,000 \mathrm{~cm}^{-1}$ to $400 \mathrm{~cm}^{-1}$.

\subsection{1 $\beta$-carotene and linoleic acid Analysis}

$\beta$-carotene and linoleic acid content in the extract were analyzed using spectrophotometer at a wavelength of 450 $\mathrm{nm}$ and $195 \mathrm{~nm}$, respectively. Initially, calibration curve was prepared by measuring a standard solution $\beta$ carotene or linoleic acid at concentration of 100 to 500 $\mathrm{mg} / \mathrm{L}$. The extract solution was diluted with $\mathrm{n}$-hexane prior to analysis. $\beta$-carotene and linoleic acid content in the extract was obtained based on the absorbance of the extract compared with the calibration curve.

\subsubsection{Carrageenan analysis}

$3 \mathrm{ml}$ of the extract was mixed with $90 \%$ ethanol in the evaporating disk. The solution then stirred to form a carrageenan fiber (hydrocolloid). And then the mixed solution was leaved for 30 minute at room temperature. After that, it was heated in the heater at $60^{\circ} \mathrm{C}$ for 24 hours. The results obtained were dry carrageenan sheets. Carrageenan functional group was identified by using FTIR (Fourier Transfer Infra-Red). Equation below is used to calculate the yield of carrageenan:

$$
\text { Yield }=\frac{\text { weight of dried carrageenan }}{\text { weight of dried seaweed }} \times 100 \%
$$

\subsubsection{Total Phenolic Compound (TPC) analysis}

TPC content in the extract was determined by Folin Ciocalteu reagent. $1 \mathrm{~mL}$ of extract was diluted into $2 \mathrm{~mL}$ of aquadest. Then, $1 \mathrm{~mL}$ of Folin Ciocalteu reagent was added to the solution followed by the addition of $1 \mathrm{~mL}$ $\mathrm{Na}_{2} \mathrm{CO}_{3}$ solution $(7 \%)$. And then the mixed solution was leaved for 30 minute at room temperature (in a dark room). Furthermore, the absorbance of the solution was measured with spectrophotometer at the wavelength of $750 \mathrm{~nm}$. TPC content in the extract was determined based on gallic acid standard curve at concentration of $0-200$ $\mathrm{mg} / \mathrm{L}$. TPC was expressed as $\mathrm{mg}$ gallic acid equivalent (GAE)/g sample.

\subsection{Antioxidant Efficiency analysis}

The efficiency of antioxidant was analyzed using DPPH Assay method. DPPH assay is an easy and accurate method to measure the antioxidant capacity of vegetables, fruits and extracts. DPPH is one of the organic nitrogen (free radical) that is available commercially. The antioxidant efficiency of extract was determined by adding $1000 \mu \mathrm{L}$ of extract into $2 \mathrm{~mL}$ of 25 ppm DPPH in methanol solution. Absorbance of the solution was measured using spectrophotometer at the wavelength of $516 \mathrm{~nm}$ every minute until a constant absorbance was obtained. Percentage of the remaining DPPH was calculated with the following equation:

$$
\% \mathrm{DPPH}_{\text {rem }}=100 \times \frac{[D P P H]_{r e m}}{[D P P]_{t=0}}
$$

$[\mathrm{DPPH}]_{\mathrm{rem}}$ is the absorbance of the extract at a certain time, and $[\mathrm{DPPH}]_{\mathrm{t}=0}$ is the initial absorbance of DPPH. The efficiency of radical antioxidant was calculated by the following equation:

$$
\mathrm{AE}=\frac{1}{E C_{50} \times t_{E C 50}}
$$

$\mathrm{EC}_{50}$ is the concentration of extract that caused $50 \%$ decrease in initial DPPH absorbance, and $\mathrm{t}_{\mathrm{EC} 50}$ is time needed to reach steady state at $\mathrm{EC}_{50}$ concentration.

\section{Result and Discussion}

\subsection{Extracted compounds from supercritical $\mathrm{CO}_{2}$ extraction}

As the target, the extracted compounds from supercritical $\mathrm{CO}_{2}$ extraction were $\beta$-carotene and linoleic acid. Based on the result of the analysis with UV-VIS spectrophotometer, the content of $\beta$-carotene and linoleic acid in the extract from Eucheuma cottonii were 209.91 and $321.03 \mu \mathrm{g} / \mathrm{g}$ samples, respectively, while for Gracilaria $s p$ the content of $\beta$-carotene and linoleic acid in the extract were 219.99 and $286.52 \mu \mathrm{g} / \mathrm{g}$ samples. The extracted carotenoids from E. cottonii was higher than the extracted carotenoids reported by Warkoyo and Saati [6]. The reported that the highest carotenoids extracted from 3 types of E. cottonii was $1.412 \mathrm{mg} / 100 \mathrm{~g}$ sample 
extracted from red $E$. cottonii with ethanol. It indicated that supercritical $\mathrm{CO}_{2}$ extraction could increase the extracted carotenoids from E. cottonii as well as from Gracilaria sp.

\subsection{Functional group of carrageenan}

The FTIR analysis is used to determine the presence of molecular functional groups present in a sample, in which the similarity of functional groups present between the standard and the analyzed sample has a group identical to the carrageenan standard groups.

The spectra of the carrageenan product obtained from the extraction using FTIR shows that the carrageenan product has met the standard carrageenan specification, because the functional groups present in the sample spectrum are identical to the standard spectrum of the carrageenan type as shown in Figure 3. In the FTIR spectra of the carrageenan compounds obtained in Figure 4 shows the presence of sulphate ester in the range 1210$1260 \mathrm{~cm}^{-1}$, glycoside bonds in the range $1010-1080 \mathrm{~cm}^{-1}$,

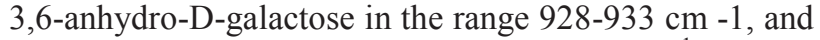
D-galactose-4-sulfate in the range $840-850 \mathrm{~cm}^{-1}$. Thus it can be concluded that the extracted carrageenan is a kappa-carrageenan.

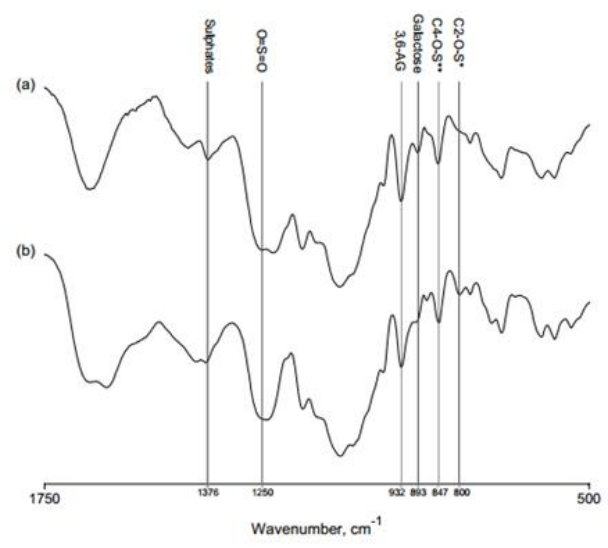

Fig. 3. Standart FTIR spectrum [7]

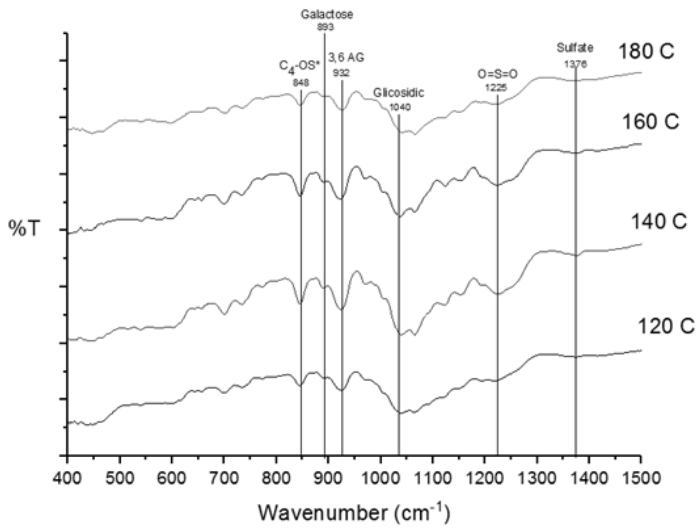

Fig. 4. Spectrum FTIR on Gracilaria $s p$ carrageenan at various temperatures and pressure of $3 \mathrm{MPa}$

\subsection{Effect of extraction temperature on the yield of carrageenan}

As shown in Figure 5, the carrageenan yields increased as the operating temperature increase. In other words, the solvent can extract optimally when the temperature is increased.

In general, the extracted substance would increase at higher temperatures due to the increasing solubility of the substance at higher temperatures [8]. It can be happened because an increase in operating temperature will result in a decrease in surface tension and the viscosity of the solute, furthermore the extraction efficiency will increase [9]. This is consistent with the experiments which states that the increase of the extraction temperature linear to the yield of carrageenan [10].

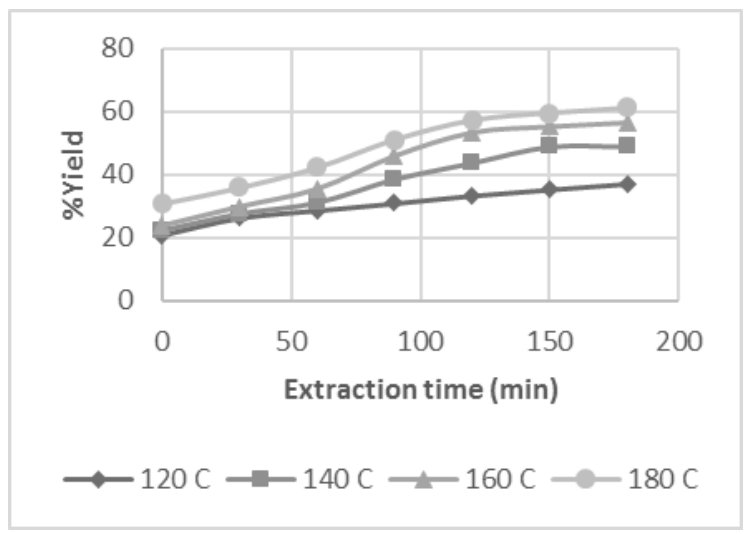

Fig. 5. The Effect of Temperature on Eucheuma cottonii Carrageenan at $7 \mathrm{MPa}$ Pressure

\subsection{Effect of extraction pressure on the yield of carrageenan}

Similar with the temperature, the yield of carrageenan also increased as the increase of the operating pressure. Figure 6 shows the increase of pressure causes the increase of the solubility of the extract in solvent, so the carrageenan will be extracted more. In addition, with the increase in pressure, the number of solvents (subcritical water) per unit volume is greater, and as the result the solubility of the extract in the solvent will increase.

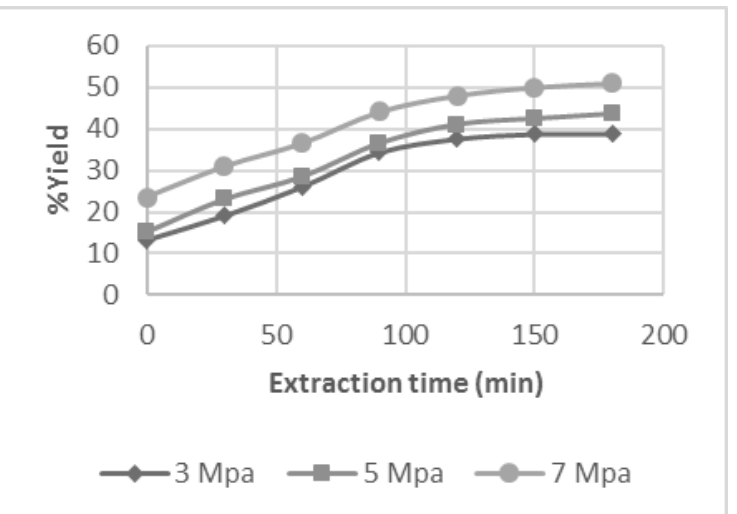

Fig. 6. The Effect of Pressure Against Yield of Gracilaria $s p$ Carrageenan at Temperature $140^{\circ} \mathrm{C}$ 


\subsection{Effect of extraction temperature on the total phenolic compound (TPC)}

Yield of total phenolic compound (TPC) increases as the operating temperature increases as shows in Figure 7.

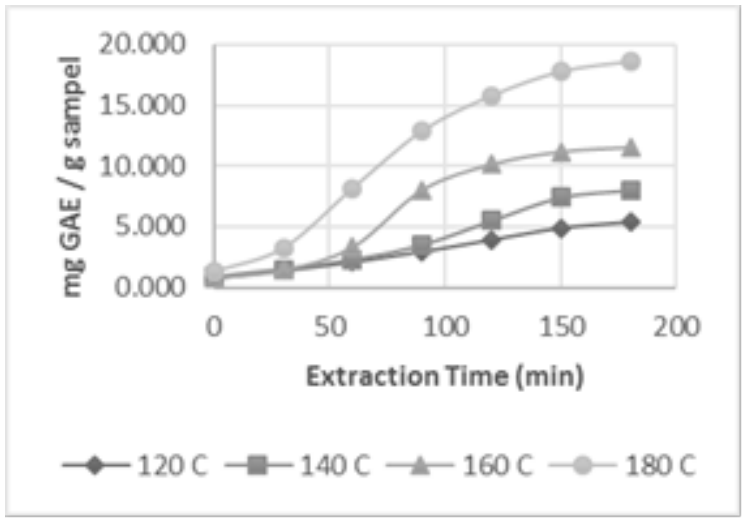

Fig. 7. Effect Analysis of Temperature on Total Phenolic Compound Eucheuma cottonii at $5 \mathrm{MPa}$ Pressure

The extracted TPC increased obviously with an increasing extraction temperature. It can be happened because the higher temperature changes affected the solubility of phenolic compounds in water, therefore the solvent (subcritical water) is able to extract seaweed optimally. In addition, As the temperature increases, the permittivity constant of the water falls, so that the phenol becomes more soluble in water.

\subsection{Effect of extraction pressure on the Total Phenolic Compound (TPC)}

As shown in Figure 8, the effect of operating pressure on the total content of phenol is not very noticeable because the pressure interval taken is too low. In addition, this is also due to the polarity of water that is not influenced by the pressure. For example, at a temperature of $100^{\circ} \mathrm{C}$, an increase in pressure from $10 \mathrm{MPa}$ to $20 \mathrm{MPa}$ only raises the dielectric constant from 55.9 to 56.2 [11].

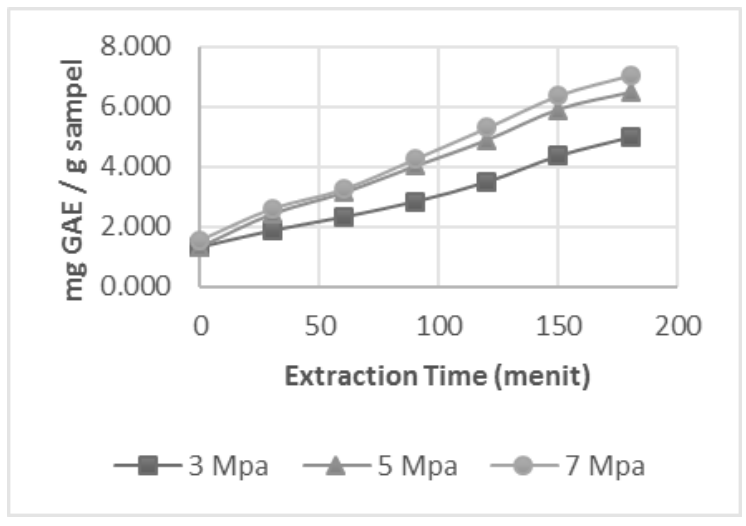

Fig. 8. Effect Analysis of Pressure on Total Phenolic Compound Gracilaria sp at Temperature $140^{\circ} \mathrm{C}$

\subsection{Antioxidant Efficiency}

Figure 9 shows \%DPPH measurement for antioxidant activity of $E$. cottonii. The decreasing \%DPPH in antioxidant activity was caused by the longer incubation time between the extract and DPPH solution as free radical. The seaweed extract acts as an antioxidant that reduce free radical (DPPH) compounds into non-radical compounds. And this can be proved when DPPH concentrations reach $50 \%$ of the initial DPPH concentrations.

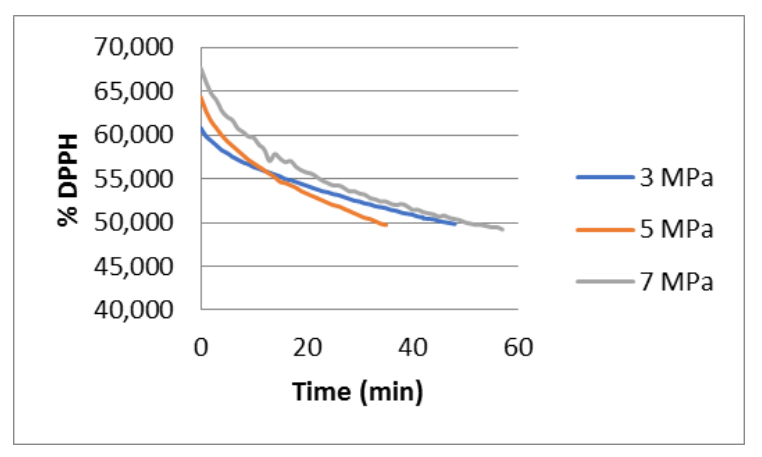

Fig. 9. Decreasing \% DPPH Antioxidant Analysis of Eucheuma cottonii at $140^{\circ} \mathrm{C}$

Eucheuma cottonii contains phytochemicals such as vitamin C, flavonoids, tannins, riboflavin [6]. Gracilaria $s p$ are also said to have antioxidant sources such as carotenoids, pigments, flavonoids, terpenes, steroids, tannins, alkaloids, phenols and glycosides in abundant amounts [12].

Table 1 shows effect of subcritical water extraction conditions on the antioxidant efficiency of the extract. The highest antioxidant efficiency (AE) was obtained at the operating temperature of $180^{\circ} \mathrm{C}$ and pressure of 7 $\mathrm{MPa}$. The efficiency of this antioxidant depends on the concentration of antioxidants contained in the extract and the time it takes the extract to reduce the concentration of DPPH per minute. The smaller the concentration of antioxidants needed to react with $\mathrm{DPPH}$, the greater the $\mathrm{AE}$ value obtained. The faster the time required by antioxidants to react with DPPH, the greater the AE value obtained. So, the greater the AE value of an extract, the greater the ability of the extract to fight the free radicals. 
Tabel 1 Antioxidant Efficiency of Extract at Various Operating Conditions

\begin{tabular}{|c|c|c|c|}
\hline Seaweed & $\begin{array}{c}\text { Temperature } \\
\left({ }^{\circ} \mathrm{C}\right)\end{array}$ & $\begin{array}{c}\text { Pressure } \\
\text { (Mpa) }\end{array}$ & $\operatorname{AE}\left(\operatorname{Min}^{-1}\right)$ \\
\hline \multirow{4}{*}{$\begin{array}{c}\text { Eucheuma } \\
\text { cottoni }\end{array}$} & 120 & \multirow{8}{*}{3} & 0.0016 \\
\hline & 140 & & 0.0181 \\
\hline & 160 & & 0.0123 \\
\hline & 180 & & 0.0636 \\
\hline \multirow{4}{*}{$\begin{array}{c}\text { Gracilaria } \\
s p\end{array}$} & 120 & & 0.004 \\
\hline & 140 & & 0.018 \\
\hline & 160 & & 0.08 \\
\hline & 180 & & 0.0735 \\
\hline \multirow{4}{*}{$\begin{array}{c}\text { Eucheuma } \\
\text { cottonii }\end{array}$} & 120 & \multirow{8}{*}{5} & 0.0018 \\
\hline & 140 & & 0.0186 \\
\hline & 160 & & 0.049 \\
\hline & 180 & & 0.8266 \\
\hline \multirow{4}{*}{$\begin{array}{c}\text { Gracilaria } \\
s p\end{array}$} & 120 & & 0.0056 \\
\hline & 140 & & 0.0193 \\
\hline & 160 & & 0.2108 \\
\hline & 180 & & 0.2984 \\
\hline \multirow{4}{*}{$\begin{array}{c}\text { Eucheuma } \\
\text { cottonii }\end{array}$} & 120 & \multirow{8}{*}{7} & 0.005 \\
\hline & 140 & & 0.026 \\
\hline & 160 & & 0.1709 \\
\hline & 180 & & 4.9636 \\
\hline \multirow{4}{*}{$\begin{array}{c}\text { Gracilaria } \\
s p\end{array}$} & 120 & & 0.0073 \\
\hline & 140 & & 0.023 \\
\hline & 160 & & 1.2323 \\
\hline & 180 & & 1.404 \\
\hline
\end{tabular}

\section{Conclusion}

Phytochemical compounds from E. cottonii and Gracilaria $s p$ have been separated and extracted by supercritical $\mathrm{CO}_{2}$ and subcritical water. The content of $\beta$ carotene and linoleic acid in the extract obtained by supercritical $\mathrm{CO}_{2}$ were 209.91 and $321.025 \mu \mathrm{g} / \mathrm{g}$ sample, respectively, for E. cottonii, and 219.99 and $286.52 \mu \mathrm{g} / \mathrm{g}$ sample, respectively, for Gracilaria sp. After supercritical $\mathrm{CO}_{2}$ extraction, the residue was extracted by subcritical water to obtain high concentration of polar compounds (carrageenan and phenolic compounds) with high antioxidant activity. The maximum yield of carrageenan and the content of TPC extracted by subcritical water were $65.54 \%$ and $24.74 \mathrm{mg}$ GAE/g sample, respectively. Based on the results the extraction method effectively separated non-polar and polar compounds, then increased the antioxidant efficiency of extract. Furthermore, the extraction method may be applied in pharmaceutical industry.

This research was supported by a grant from Directorate General of Science, Technology and Higher Education, Ministry of Research, Technology and Higher Education of the Republic of Indonesia through a competitive research grant Penelitian Berbasis Kompetensi contract no.: 524/PKS/ITS/2017.

\section{References}

1. A. Diharmi, D. Fardiaz, N. Andarwulan, E.S. Heruwati. J. Perikanan dan Kelautan 16, 117 (2011)

2. A.B Ikrom, Aunurokhim. J. Teknik POMITS 2, (2013) ISSN: 2337-3539

3. M.V. Palmer, S.S.T. Ting, Food Chem. 52, 345 (1995).

4. S. Machmudah, K. Kitada, M. Sasaki, M. Goto, J. Munemasa, M. Yamagata, Ind. Eng. Chem. Res. 50, 2227 (2011).

5. I. Sereewatthanawut, S. Prapintip, K. Watchiraruji, M. Goto, M. Sasaki, A. Shotipruk, Bioresour. Technol. 99, 555 (2008).

6. Warkoyo, E.A. Saati, Makara J. Technol. 15, 5 (2011).

7. R. Tuvikene, K. Truus, M. Vaher, T. Kailas, G. Martin, P. Kersen, Proc. Estonian Acad. Sci. Chem. 55, 40 (2006).

8. M.Z.Ozel, F. Gogus, A.C. Lewis, Food Chem. 82, 381 (2003).

9. H.J. Mockel, G. Welter, H. Melzer, J. Chromatogr. A 388, 255 (1987).

10. V. Webber, S.M. de Carvalho, P.J. Ogliari, L. Hayashi, P.L. Barreto, Cienc. Tecnol. Aliment. 32, 812 (2012).

11. Wahyudiono, S. Machmudah, M. Goto, Engineering J. 17, 1 (2013).

12. K.L. Sreejamole, P.M. Greeshma, Indian J. Nat. Prod. Resourc. 4, 233 (2013). 